DOI: $10.17957 / \mathrm{IJAB} / 15.1791$

http://www.fspublishers.org

\title{
Distribution of Culturable Myxobacteria in Central Inner Mongolia and their Activity against Phytophthora infestans
}

\author{
Zhi Hua $\mathrm{Wu}^{1,2,3}$, Xue Han Wang ${ }^{1}$, Qiang Ma ${ }^{1}$, Yi Xiu Ding ${ }^{1}$, Pu Yu Zhao ${ }^{1}$ and Hui Rong Liu ${ }^{1 *}$ \\ ${ }^{1}$ College of Life Sciences, Inner Mongolia Agricultural University, Hohhot 010010, P. R. China \\ ${ }^{2}$ Baotou Teachers' College, Baotou 014030, P. R. China \\ ${ }^{3}$ The Second Affiliated Hospital of Baotou Medical College, Inner Mongolia University of Science and Technology, Baotou \\ 014030, P. R. China
}

*For correspondence: huirong_liu@imau.edu.cn; wuzhihuaqueen@163.com

Received 06 November 2020; Accepted 28 January 2021; Published 10 May 2021

\begin{abstract}
Myxobacteria can produce rich and varied biological active substances against bacteria, fungi and viruses, which have great development and research value in medicine and agriculture. In this study, the diversity of culturable myxobacteria in central Inner Mongolia in China was studied and the effects of soil utilization mode, soil type and environmental parameters on the distribution of myxobacteria in this region were analyzed. Furthermore, the activities of myxobacteria against potato late blight pathogen were tested. The results showed that Myxococcus, Corallococcus, Pyxidicoccus, Cystobacter, Archangium and Mellittangium were the dominant genera of myxobacteria in this region. Soil utilization mode and soil types have obvious influence on the distribution of myxobacteria. The populations of myxobacteria were abundant in grassland and cultivated land samples, but few in woodland and unused land samples. The diversity of myxobacteria in the soil samples from fuvoaquic soils, grey-cinnamon soils, castanozems, and bog soils was relatively rich, while the richness of myxobacteria in aeolian soils, solonetzs, skeletol soils and castano-cinnamon soils was poor. There was no significant correlation between myxobacteria distribution and soil environmental parameters (including the water content, $\mathrm{pH}$ value, content of organic matter, content of available phosphorus, content of hydrolytic nitrogen and content of available potassium). Most of the myxobacterial strains isolated in this area $(83 \%)$ showed the activity against $P$. infestans, among which the proportion of the disease-resistant strains belonging to Myxococcus and Corallococcus was high, the proportion of the strains belonging to Cystobacter and Mellittangium in the medium, and the proportion of the strains belonging to Pyxidicoccus and Archangium low. The completion of this work will enrich the myxobacteria resource bank in Inner Mongolia and lay a foundation for the further study on myxobacteria and the development of biological pesticide against potato late blight. (C) 2021 Friends Science Publishers
\end{abstract}

Keywords: Myxobacteria; Diversity; Isolation; Identification; Potato late blight; Phytophthora infestans

\section{Introduction}

Myxobacteria, a group of gram-negative bacteria (Kim et al. 2016), with social behavior, complex multicellular behavior and morphogenesis (Sun et al. 2016), are considered to be higher prokaryotes and known for their predatory lifestyle (Livingstone et al. 2018). A typical feature of myxobacteria is that the cells move by gliding or creeping, often presenting a thin, translucent film on a solid plate, forming many concentric radial lines (Reichenbach 2001). The vegetative cells are rod-shaped, and the cell membrane is elastic (Zhang 2005). They are propagated in a binary fission manner and grow slowly. Under a variety of adverse conditions, such as nutrient deficiency, myxobacteria form visible fruiting bodies through a complex multicellular behavior. Fruiting bodies are usually of various shapes and sizes, with bright colors such as bright yellow, red, orange, brown, or black (Anqel et al. 2017). Myxobacteria are good natural drug screening resources and have become a large group of microbial groups with great potential for research and development (Diez et al. 2012). Bioactive substances produced by myxobacteria have antibacterial, antifungal, anticancer, thrombolytic, antitumor, hypoglycemic, hypotensive activities and etc. (Zhang et al. 2011; Okanya et al. 2012). Myxobacteria have been actively screened for natural products for several decades, with more than 100 core structures and over 500 derivatives now having been published (Herrmann et al. 2017). Moreover, myxobacteria have great potential for biosynthesis and 50\% 100\% of myxobacteria can synthesize secondary metabolites with biological activity (Wenzel and Müller 2009). In prokaryotes, myxobacteria rank just behind Actinomyces and Bacillus in the number of biologically active substances (Wang and Ma 2010). However, the ratio of positive 
bacteria with bacteriostatic activity is higher than that of Actinomycetes. Because myxobacteria can produce many bioactive substances with novel structure and unique mechanism of action, they have become the "micro-factory" of secondary metabolites with biological activity (Weissman and Müller 2009). Therefore, more and more attention has been paid to the research of myxobacteria.

Potato is the fourth largest food crop in the world after rice, wheat, and corn. The most serious disease of potato is potato late bright, which is caused by Phytophthora infestans (Cui 2018). P. infestans is a devastating pathogen that causes death of potato stems and tuber mainly by invading the leaves, stems, and tubers of the plant (Haas et al. 2009). Due to the limitation of cognitive level on some scientific problems such as the pathogenic mechanism and the reproductive regulation mechanism of $P$. infestans, there is still no way to effectively prevent and control potato late blight, which has seriously hindered the production and industrialization of potato (Ren et al. 2016).

Baotou, Hohhot, Wulanchabu and Xilinguole are distributed in the central part of Inner Mongolia with special geographical conditions (Xu et al. 2001; Chen and Gong 2005). In this area, the terrain is dominated by plateaus and there are many types of soils. The precipitation gradually decreases from east to west under the influence of the topography and the distance from the ocean. The area has a typical mid-temperate zone monsoon climate with obvious climate change in the four seasons and large annual and daily temperature differences. Under these special geographical conditions, there are bound to be rich and diverse resources of myxobacteria. However, so far, there have been few reports on myxobacteria resources and their biological activities in central region of Inner Mongolia. In this study, myxobacteria were isolated from 139 of soil samples from the central region of Inner Mongolia and the correlation of diversity of culturable myxobacteria with environmental factors in this region was analyzed. Furthermore, the activities of the myxobacterial strains against $P$. infestans were determined.

\section{Materials and Methods}

\section{Soil sample collection}

Soil samples were collected from the four regions in the central Inner Mongolia Autonomous Region, Baotou, Hohhot, Wulanchabu and Xilinguole. A total of 139 soil samples, including 15 soil types and four utilization modes, were collected from the upper layer of the soil $(5-20 \mathrm{~cm}$ depth) (Table 1).

\section{Determination of soil parameters}

The moisture content of the samples was determined by drying method (Ye and Zhang 1984). The $\mathrm{pH}$ value was determined according to the Ecology Common
Experimental Research Methods and Techniques (Zhang 2006). $\mathrm{NaHCO}_{3}$ leaching - molybdenum antimony and colorimetric method was used to determine the available phosphorus of soil samples (Xing et al. 2011). Soil available potassium was determined by tetraphenylborate nephelometry (Li et al. 1982). The alkaline hydrolysis diffusion method was used to determine the content of hydrolyzable nitrogen ( $\mathrm{Li}$ 2010) and the potassium dichromate-volumetric method was used to determine the organic matter contents in the soils (Ji 2005).

\section{Isolation of myxobacteria}

Pretreatment of soil samples: The soil samples that had been naturally air-dried and screened at 60 mesh were baked at $58^{\circ} \mathrm{C}$ for $1 \mathrm{~h}$ to remove the poor heat resistance of miscellaneous bacteria. Approximately $30 \mathrm{~g}$ of the soil samples were placed in a $90 \mathrm{~mm}$ Petri dish, soaked overnight at room temperature with cycloheximide solution at a final concentration of $100 \mu \mathrm{g} \mathrm{mL}^{-1}$ to remove a portion of the mold and yeast.

Rabbit dung pellets inducing method: The pretreated soil samples were poured into the ST21CX solid culture dish and paved. Three sterilized rabbit dung pellets were embedded in half and the culture dishes were incubated at $30^{\circ} \mathrm{C}$ for 6 days. Continue to observe the formation of myxobacteria fruiting bodies (Liu et al. 2011).

Escherichia coli inducing method: Escherichia coli DH$5 \alpha$ bacteria solution $(20 \mu \mathrm{L})$ was added to $200 \mathrm{~mL}$ of $\mathrm{LB}$ liquid medium ( $\mathrm{Wu} 2018$ ) and the cells were shaken overnight. The next day, Escherichia coli $\mathrm{DH}-5 \alpha$ bacteria solution was centrifuged and the cell precipitate was rowed three uniform and thick parallel lines on WCX medium. Pretreated soil samples with soybean size were picked and placed on the end of three parallel lines, and then the culture dishes were incubated at $30^{\circ} \mathrm{C}$ (Sood et al. 2014).

Filter paper inducing method: A sterilized filter paper was placed on the ST21CX medium as the only carbon source and energy source. Pretreated soil samples with soybean size were placed in different positions on the filter paper, and the culture dishes were incubated at $30^{\circ} \mathrm{C}$ (Gaspari et al. 2005).

\section{Purification of myxobacteria}

Directly pick the fruiting body: The myxobacteria were identified and the border of characteristic colonies or the head of fruiting bodies was picked directly on fresh VY/2 medium with a sterile inoculation needle to remove a portion of the larger and immobile bacteria (Guo et al. 2007). Fruiting body of myxobacteria on the filter paper or the corroded filter paper was transferred to fresh ST21CX medium with sterilized filter paper by a sterile toothpick at $30^{\circ} \mathrm{C}$ constant temperature culture. This method requires repeated transfer, until there is no other bacterial growth in the medium. 
Wu et al. / Intl J Agric Biol, Vol 25, No 6, 2021

Table 1: Details of the soil samples

\begin{tabular}{|c|c|c|c|c|c|}
\hline Different types of soil samples & Cultivated land & Grassland & Woodland & Unused land & Total \\
\hline Fluvo-aquic soil & 5 & 8 & & 2 & 15 \\
\hline Grey-cinnamon & 8 & 10 & 2 & 2 & 22 \\
\hline Castanozems & 13 & 19 & 1 & 1 & 34 \\
\hline Litho soil & - & 2 & - & 1 & 3 \\
\hline Saline & 3 & 3 & 1 & 1 & 8 \\
\hline Alluvial soil & 1 & 1 & 1 & - & 3 \\
\hline Brown pedocals & 3 & 9 & 1 & - & 13 \\
\hline Gray forest soil & 2 & 3 & 2 & - & 7 \\
\hline Bog soil & 2 & 3 & 1 & - & 6 \\
\hline Aeolian soil & 1 & 2 & 1 & - & 4 \\
\hline Meadow soil & 5 & 6 & - & - & 11 \\
\hline Solonetzs & - & 1 & - & - & 1 \\
\hline Chernozem & 3 & 4 & - & - & 7 \\
\hline Skeletol soil & - & 1 & - & - & 1 \\
\hline Castano-cinnamon soil & 2 & 2 & - & - & 4 \\
\hline Total & 48 & 74 & 10 & 7 & 139 \\
\hline
\end{tabular}

-: The number of samples was 0

Secondary inducing method: Bacteriolytic myxobacteria that cannot be directly purified were transferred into fresh WCX medium with three uniform and thick E. coli lines and incubated at $30^{\circ} \mathrm{C}$. Then the fruiting bodies were picked from the edges of the expanded colonies to the VY/2 medium to further culture.

\section{Examination and preservation of myxobacteria}

The fruiting bodies of the strains were incubated in the CAS liquid medium and shaken culture for $36 \mathrm{~h}$, then to observe whether there was turbidity in the CAS liquid medium. As the myxobacteria grow slowly in nutrient-rich medium, while the other miscellaneous bacteria grow fast relatively, so the clarification of CAS liquid culture medium can be considered that the strain has been pure. The purified myxobacteria strains were stored in $20 \%$ sterilized glycerol at $-80^{\circ} \mathrm{C}$ for a long time.

\section{Identification of myxobacteria}

Morphological observation: The Nikon SMZ745 stereomicroscope and Sony digital camera were used to observe and photograph the colony morphology and fruiting bodies of myxobacteria on the VY/2 medium and ST21CX medium.

Molecular identification: The total chromosomal DNA was extracted as described by Zhou et al. (2004). The first set of primers (forward 27F: 5'-AGAGTTTGATCCTGGCTCAG3', and reverse 1495R: 5'-CTACGGCTACCTTGTTACGA$3^{\prime}$ ) was designed to amplify the partial $16 \mathrm{~S}$ rDNA of myxobacteria (Zhang et al. 2010). The reaction started with denaturation at $94^{\circ} \mathrm{C}$ for $30 \mathrm{~s}$, followed by primer annealing at $55^{\circ} \mathrm{C}$ for $45 \mathrm{~s}$ and primer extension at $72^{\circ} \mathrm{C}$ for $90 \mathrm{~s}$. After 30 cycles of reaction, an extension step was followed at $72^{\circ} \mathrm{C}$ for $5 \mathrm{~min}$. The PCR products were sent to Beijing Liuhe Huada Gene Technology Co., Ltd. for sequencing. The 16S rDNA sequences of the tested strains were compared with the known sequences in the GenBank database by BLAST in NCBI.

\section{Activity analysis of myxobacteria against $P$. infestans}

The activity of the purified myxobacterial strains against $P$. infestans was detected by the plate confrontation culture method (Li et al. 2011). The phytopathogenic oomycete $P$. infestans was cultured on a rye medium in a 9-cm dish at $18^{\circ} \mathrm{C}$ for 3 days in the dark until the colony grew to approximately $1 \mathrm{~cm}$ in diameter. Agar block of purified strains was placed $1 \mathrm{~cm}$ away from the front of the colony. After incubating at $18^{\circ} \mathrm{C}$ for 8 days, the distance between the edge of the colony and the agar block (control: $0 \mathrm{~mm}$ ) was measured. The resistance of each strain to $P$. infestans was tested three times.

\section{Data processing}

The preliminary processing and mapping of the data was done using Excel 2010 and the correlation analysis was done using SPSS V. 24.0.

\section{Results}

\section{The determination of soil environmental parameters}

The parameters of 139 soil samples were measured and compared with the soil nutrient grading standards of the second national soil survey in China (Table 2). The results showed that about $38.85 \%$ of the soil samples were alkaline. $49.64 \%$ of the soil samples were neutral and $11.51 \%$ of the soil samples were acidic. The water content of $87.77 \%$ soil samples was lower than $16 \%$, which was in the state of light drought to severe drought. For the content of organic matter, $56.12 \%$ of soil samples were at a low to very low level. The content of available phosphorus was distributed evenly, with a certain proportion in each grade. Of which, $43.17 \%$ of soil samples were at medium level, $36.70 \%$ at low to extremely low level and $20.15 \%$ at high to very high level. As for the content of available potassium, $31.65 \%$ of soil samples were at medium level and $46.76 \%$ at low to extremely low level. 
Distribution of Culturable Myxobacteria / Intl J Agric Biol, Vol 25, No 6, 2021

Table 2: Nutrient grade distribution of soil samples from the central region of Inner Mongolia

\begin{tabular}{|c|c|c|c|c|c|c|}
\hline \multirow{2}{*}{$\begin{array}{l}\text { Environmental parameter } \\
\text { levels of soil samples }\end{array}$} & \multicolumn{6}{|c|}{ Percentage of environmental parameters of soil samples at different levels (\%) } \\
\hline & Water content & $\mathrm{pH}$ value & $\begin{array}{l}\text { Content of organic } \\
\text { matter }\end{array}$ & $\begin{array}{l}\text { Content of available } \\
\text { phosphorus }\end{array}$ & $\begin{array}{l}\text { Content of hydrolyzed } \\
\text { nitrogen }\end{array}$ & $\begin{array}{l}\text { Content of available } \\
\text { potassium }\end{array}$ \\
\hline I & & 3.60 & 10.07 & 5.76 & 5.76 & 6.47 \\
\hline III & 5.04 & 49.64 & 23.02 & 43.17 & 11.51 & 31.65 \\
\hline IV & 15.83 & 10.07 & 37.41 & 28.06 & 23.74 & 28.06 \\
\hline V & 27.34 & 1.44 & 18.71 & 2.88 & 31.56 & 10.79 \\
\hline
\end{tabular}

I: Strong alkaline or very rich. II: Slightly alkaline or rich. III: Neutral or suitable. IV: Slightly acidic or low. V: Highly acidic or very low. VI: Extremely acidic or extremely low

Table 3: Number of myxobacterial strains isolated and purified by different methods

\begin{tabular}{llll}
\hline Methods of isolation & $\begin{array}{l}\text { No. of } \\
\text { isolated } \\
\text { strains }\end{array}$ & $\begin{array}{l}\text { No. of } \\
\text { purified } \\
\text { strains }\end{array}$ & $\begin{array}{l}\text { Purification rate } \\
\text { of strains }(r / \%)\end{array}$ \\
\hline Rabbit dung pellets inducing method & 158 & 153 & 96.83 \\
Escherichia coli inducing method & 245 & 231 & 94.29 \\
Filter paper inducing method & 283 & 0 & 0 \\
Total number & 686 & 384 & 55.98 \\
\hline
\end{tabular}

However, the content of hydrolyzed nitrogen was generally in a state of deficiency, with $79.04 \%$ of soil samples at a low to extremely low level. These results indicated that soil fertility was generally poor in central Inner Mongolia.

\section{Isolation and identification of myxobacteria}

The myxobacteria were isolated and identified from 139 soil samples collected from the central region of Inner Mongolia. A total of 686 strains with morphological characteristics of myxobacteria were isolated and 384 strains of which were purified and identified, with an average purification rate of $55.98 \%$ (Table 3). Among them, the number of strains isolated by filter paper inducing method was the most, while the number of strains isolated by rabbit dung pellets inducing method was the least. However, the strains isolated by rabbit dung pellets inducing method were the easiest to be purified, and the purification rate of this method was the highest. The purification rate of filter paper inducing method was the lowest.

According to the classification standards of Bergey's Manual of Systemaic Bacteriology (Boone and Castenholz 2004), from the characteristics of the color and morphology of colonies and fruiting bodies of the purified strains and their gliding movement on the plate, these strains can be preliminarily classified into six genera, including Myxococcus, Corallococcus, Pyxidicoccus, Cystobacter, Archangium and Melittangium (Fig. 1 and 2).

The purified 384 strains were identified further by $16 \mathrm{~S}$ rRNA gene sequences. The results showed that the similarities between the $16 \mathrm{~S}$ rRNA gene sequences of all strains and the sequences reported in the GenBank database were more than 97\%. Phylogenetic tree analysis with Neighbor-Joining Tree Algorithm showed that all strains could be divided into 2 large branches and 4 small branches. Myxococcus $、$ Corallococcus and Pyxidicoccus were on the

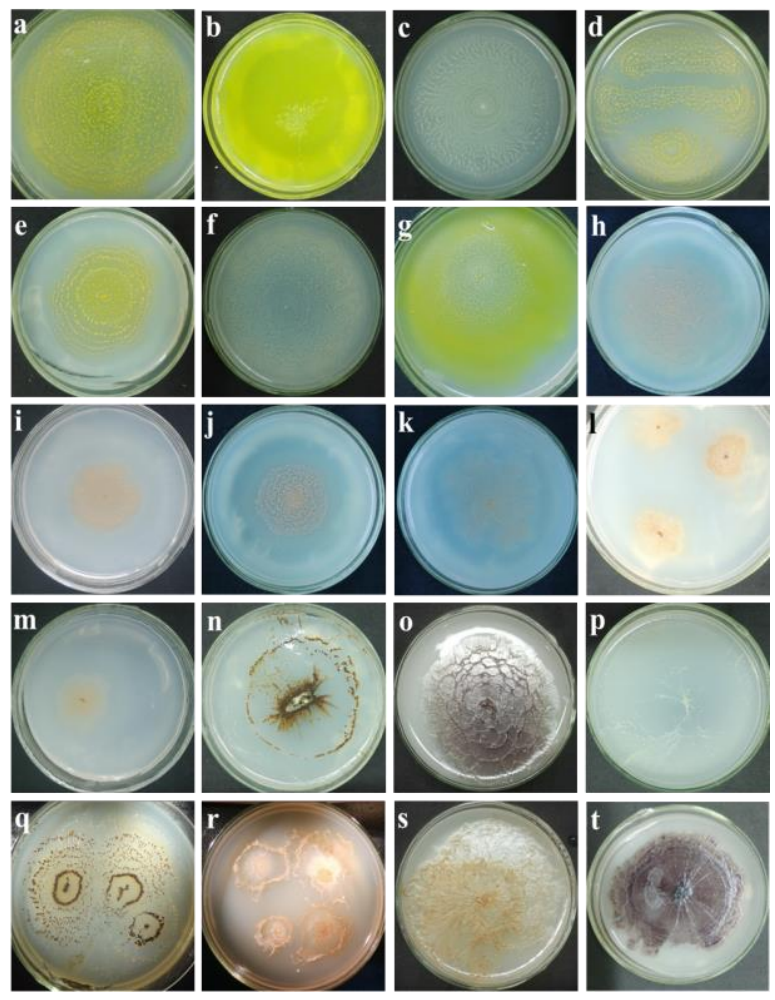

Fig. 1: Colony morphology of myxobacteria isolated by the rabbit dung pellets inducing method and $E$. coli inducing method (a) Myxococcus fulvus (b) Myxococcus virescens (c) Myxococcus coralloides (d) Myxococcus xanthus (e) Myxococcus favescens (f) Myxococcus stipitatus (g) Myxococcus macrosporus (h) Corallococcus coralloides (i) Corallococcus exiguus (j) Corallococcus macrosporus (k) Corallococcus spp. (l) Pyxidicoccus fallax (m) Pyxidicoccus spp. (n) Cystobacter badius (o) Cystobacter violaceus (p-q) Cystobacter spp. (r) Archangium gephyra (s) Archangium spp. (t) Melittangium spp.

same large branch, belonging to Myxococcaceae. The other large branch included Archangium, Cystobacter and Melittangium, all belonging to Cystobacteraceae. According to the morphological classification of myxobacteria, both Myxococcaceae and Cystobacteraceae belonged to the Cystobacterineae (Fig. 3).

Through morphological observation and 16S rRNA gene sequences analysis, all of 348 strains belonged to Cystobacterineae, including 278 strains of Myxococcaceae and 70 strains of Cystobacteraceae. These strains were classified into six genera, including Myxococcus, Corallococcus, Pyxidicoccus, Cystobacter, Archangium and 


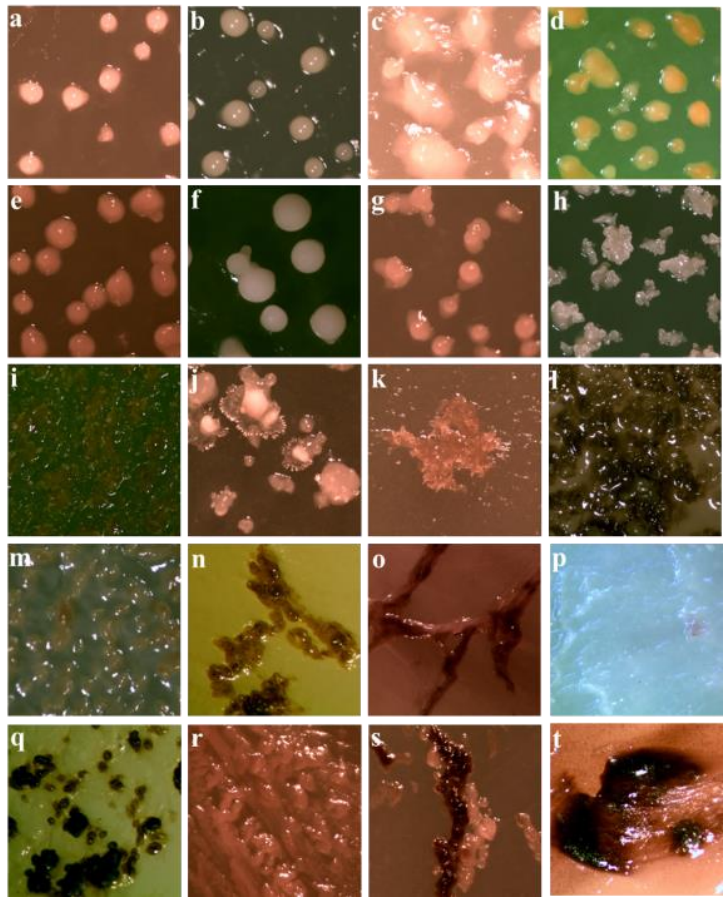

Fig. 2: Fruiting body morphology of myxobacteria isolated from rabbit dung pellets inducing method and $E$. coli inducing method $(30 \times)$

(a) Myxococcus fulvus, (b) Myxococcus virescens, (c) Myxococcus coralloides, (d) Myxococcus xanthus, (e) Myxococcus favescens, (f) Myxococcus stipitatus, (g) Myxococcus macrosporus, (h) Corallococcus coralloides, (i) Corallococcus exiguous, (j) Corallococcus macrosporus, (k) Corallococcus spp., (l) Pyxidicoccus fallax, (m) Pyxidicoccus spp.,(n) Cystobacter badius, (o) Cystobacter violaceus, (p-q) Cystobacter spp., (r) Archangium gephyra, (s) Archangium spp. and (t) Melittangium spp.

Melittangium. Among them, 193 strains belonged to Myxococcus (Myxococcus fulvus 67 strains, Myxococcus virescens 41 strains, Myxococcus coralloides 6 strains, Myxococcus xanthus 45 strains, Myxococcus favescens 19 strains, Myxococcus stipitatus 10 strains, Myxococcus macrosporus 5 strains). 76 strains belonged to Corallococcus (Corallococcus coralloides 39 strains, Corallococcus exiguous 27 strains, Corallococcus macrosporus 8 strains, Corallococcus spp. 2 strains). 9 strains belonged to Pyxidicoccus (Pyxidicoccus fallax 8 strains, Pyxidicoccus spp. 1 strain).45 strains belonged to Cystobacter (Cystobacter violaceus 25 strains, Cystobacter badius 16 strains, Cystobacter spp. 4 strains).10 strains belonged to Archangium (Archangium gephyra 8 strains, Archangium spp. 2 strains). 15 strains belonged to Mellittangium (Mellittangium spp. 15 strains).

\section{Distribution of myxobacteria in soil samples of different utilization types}

It could be clearly seen from Table 4 that the average number of the myxobacterial strains isolated and purified from cultivated land soil samples was the highest, repectively 5.02 and 2.69 , followed by that of grassland and woodland soil samples. The average number of the myxobacteria strains isolated and purified from the unused land soil samples was the lowest.

The myxobacteria strains belonging to Myxococcaceae and Cystobacteraceae were all obtained from soil samples of four different utilization types. Of which, six genara of myxobacteria, including Myxococcus, Corallococcus, Pyxidicoccus, Cystobacter, Archangium and Melittangium, were purified from the soil samples of cultivated land, grassland and woodland, while only three genera of myxobacteria were purified from the samples of unused land, including Myxococcus, Corallococcus and Cystobacter. The average number of the strains belonging to Myxococcus, Cystobacter and Corallococcus was the highest in the cultivated land soil samples, but the lowest in the unused land soil samples. The strains belonging to Pyxidicoccus, Archangium and Mellittangium were all not purified from the unused land soil samples. The average number of the strains belonging to Mellittangium was also the highest in the cultivated land soil samples, while the average number of the strains belonging to Pyxidicoccus and Archangium was the highest in the woodland soil samples. In soil samples of four utilization types, the average number of the strains belonging to Myxococcus ranked first, followed by the average number of the strains belonging to Corallococcus, and the average number of the strains belonging to Cystobacter ranked third. The average number of the strains belonging to Pyxidicoccus, Archangium, and Mellittangium was significantly lower than the average number of the strains belonging to the other three genera, and in the unused land soil samples, the three genera were not even isolated.

\section{Distribution of myxobacteria in soil samples of different types}

It could be clearly seen from Table 5 that the average number of strains isolated from solonetzs and alluvial soils was the highest and the average number of strains purified from solonetzs was the highest, while the average number of strains isolated from chernozems was the lowest and the average number of strains purified from gray-cinnamon soils was the lowest.

Myxococcaceae and Cystobacteraceae were all purified from 15 different soil types, with differences in the varieties and quantities of the strains. Only three genera of myxobacteria were purified from aeolian soils, solonetzs, skeletol soils and castano-cinnamon soils. Four genera of myxobacteria were purified from litho soils, alluvial soils and gray forest soils. Five genera of myxobacteria were purified from saline soils, brown pedocals, meadow soils and chernozems. Six genera of myxobacteria were purified from fluvo-aquic soils, grey-cinnamon soils, castanozems, and bog soils, showing a rich diversity of myxobacteria. Of the 6 genera of myxobacteria isolated, only Myхососси was isolated from all soil types. The average number of the 
Distribution of Culturable Myxobacteria / Intl J Agric Biol, Vol 25, No 6, 2021

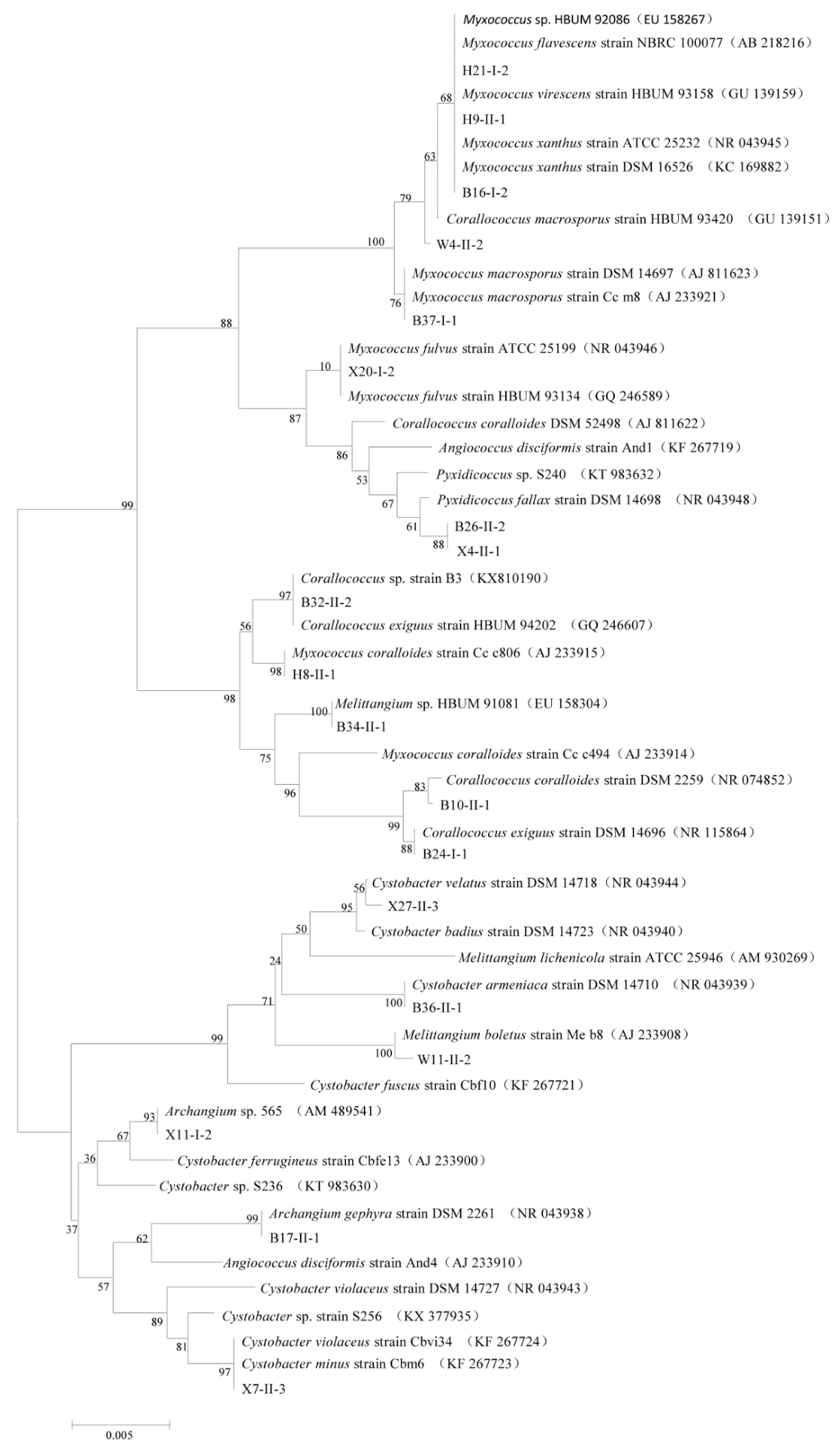

Fig. 3: Phylogenetic tree for the myxobacterial strains based on 16S rRNA gene sequences

strains belonging to Myxococcus isolated from alluvial soils and solonetzs was the highest, while the average number of the strains belonging to Myxococcus isolated from chernozems was the lowest. The strains belonging to
Corallococcus were isolated from all soil types except skeletol soils, in which the average number of strains belonging to Corallococcus was the highest in solonetzs and the lowest in bog soils. The strains belonging to Cystobacter 
Wu et al. / Intl J Agric Biol, Vol 25, No 6, 2021

Table 4: Distribution of myxobacteria in soil samples of different utilization types

\begin{tabular}{|c|c|c|c|c|c|c|c|c|c|c|c|c|c|c|c|c|}
\hline \multirow{2}{*}{$\begin{array}{l}\text { Utilization } \\
\text { types of soil } \\
\text { samples }\end{array}$} & \multirow{2}{*}{$\begin{array}{l}\text { Total } \\
\text { number of } \\
\text { the isolated } \\
\text { strains }\end{array}$} & \multirow{2}{*}{$\begin{array}{l}\text { Average number } \\
\text { of the isolated } \\
\text { strains/soil } \\
\text { sample }\end{array}$} & \multirow{2}{*}{$\begin{array}{l}\text { Total } \\
\text { number of } \\
\text { the purified } \\
\text { strains }\end{array}$} & \multirow{2}{*}{$\begin{array}{l}\text { Average number } \\
\text { of the purified } \\
\text { strains/soil } \\
\text { sample }\end{array}$} & \multicolumn{2}{|c|}{ Myхососсиs } & \multicolumn{2}{|c|}{ Corallococcus } & \multicolumn{2}{|c|}{ Pyxidicoccus } & \multicolumn{2}{|c|}{ Cystobacter } & \multicolumn{2}{|c|}{ Archangium } & \multicolumn{2}{|c|}{ Mellittangium } \\
\hline & & & & & $\begin{array}{l}\text { Total } \\
\text { number }\end{array}$ & $\begin{array}{l}\text { Average } \\
\text { number }\end{array}$ & $\begin{array}{l}\text { Total } \\
\text { number }\end{array}$ & $\begin{array}{l}\text { Average } \\
\text { number }\end{array}$ & $\begin{array}{l}\text { Total } \\
\text { number }\end{array}$ & $\begin{array}{l}\text { Average } \\
\text { number }\end{array}$ & $\begin{array}{l}\text { Total } \\
\text { number }\end{array}$ & $\begin{array}{l}\text { Average } \\
\text { number }\end{array}$ & $\begin{array}{l}\text { Total } \\
\text { number }\end{array}$ & $\begin{array}{l}\text { Average } \\
\text { number }\end{array}$ & $\begin{array}{l}\text { Total } \\
\text { number }\end{array}$ & $\begin{array}{l}\text { Average } \\
\text { number }\end{array}$ \\
\hline Cultivated land & 241 & 5.02 & 129 & 2.69 & 70 & 1.46 & 30 & 0.63 & 3 & 0.06 & 16 & 0.33 & 4 & 0.08 & 6 & 0.13 \\
\hline Grassland & 338 & 4.57 & 185 & 2.50 & 106 & 1.43 & 37 & 0.50 & 5 & 0.07 & 24 & 0.32 & 5 & 0.07 & 8 & 0.11 \\
\hline Woodland & 45 & 4.50 & 23 & 2.30 & 11 & 1.10 & 6 & 0.60 & 1 & 0.10 & 3 & 0.30 & 1 & 0.10 & 1 & 0.10 \\
\hline Unused land & 26 & 3.71 & 11 & 1.57 & 5 & 0.71 & 3 & 0.43 & 0 & 0 & 2 & 0.29 & 0 & 0 & 0 & 0 \\
\hline Total & 650 & 4.68 & 348 & 2.50 & 193 & 1.39 & 76 & 0.55 & 9 & 0.06 & 45 & 0.32 & 10 & 0.07 & 15 & 0.11 \\
\hline
\end{tabular}

Table 5: Distribution of myxobacteria in different types of soil samples

\begin{tabular}{|c|c|c|c|c|c|c|c|c|c|c|c|c|c|c|c|c|}
\hline \multirow{2}{*}{$\begin{array}{l}\text { Different types of soil } \\
\text { samples }\end{array}$} & \multirow{2}{*}{$\begin{array}{l}\text { Total } \\
\text { number of } \\
\text { the isolated } \\
\text { strains }\end{array}$} & \multirow{2}{*}{$\begin{array}{l}\text { Average } \\
\text { number of the } \\
\text { isolated strains } \\
\text { /soil sample }\end{array}$} & \multirow{2}{*}{$\begin{array}{l}\text { Total } \\
\text { number of } \\
\text { the purified } \\
\text { strains }\end{array}$} & \multirow{2}{*}{$\begin{array}{l}\text { Average } \\
\text { number of the } \\
\text { purified strains } \\
\text { / soil sample }\end{array}$} & \multicolumn{2}{|c|}{ Mухососсиs } & \multicolumn{2}{|c|}{ Corallococcus } & \multicolumn{2}{|c|}{ Pyxidicoccus } & \multicolumn{2}{|c|}{ Cystobacter } & \multicolumn{2}{|c|}{ Archangium } & \multicolumn{2}{|c|}{ Mellittangium } \\
\hline & & & & & $\begin{array}{l}\text { Total } \\
\text { number }\end{array}$ & $\begin{array}{l}\text { Average } \\
\text { number }\end{array}$ & $\begin{array}{l}\text { Total } \\
\text { number }\end{array}$ & $\begin{array}{l}\text { Average } \\
\text { number }\end{array}$ & $\begin{array}{l}\text { Total } \\
\text { number }\end{array}$ & $\begin{array}{l}\text { Average } \\
\text { number }\end{array}$ & $\begin{array}{l}\text { Total } \\
\text { number }\end{array}$ & $\begin{array}{l}\text { Average } \\
\text { number }\end{array}$ & $\begin{array}{l}\text { Total } \\
\text { number }\end{array}$ & $\begin{array}{l}\text { Average } \\
\text { number }\end{array}$ & $\begin{array}{l}\text { Total } \\
\text { number }\end{array}$ & $\begin{array}{l}\text { Average } \\
\text { number }\end{array}$ \\
\hline Fluvo-aquic soil & 72 & 4.80 & 38 & 2.53 & 21 & 1.40 & 8 & 0.53 & 1 & 0.07 & 5 & 0.33 & 1 & 0.07 & 2 & 0.13 \\
\hline Grey-cinnamon & 101 & 4.59 & 56 & 2.55 & 28 & 1.27 & 14 & 0.64 & 1 & 0.05 & 9 & 0.41 & 1 & 0.05 & 3 & 0.14 \\
\hline Castanozems & 154 & 4.53 & 84 & 2.47 & 49 & 1.44 & 19 & 0.56 & 1 & 0.03 & 10 & 0.29 & 2 & 0.06 & 3 & 0.09 \\
\hline Litho soil & 14 & 4.67 & 8 & 2.67 & 4 & 1.33 & 2 & 0.67 & 0 & 0 & 1 & 0.33 & 1 & 0.33 & 0 & 0 \\
\hline Saline & 40 & 5.00 & 22 & 2.75 & 12 & 1.50 & 5 & 0.63 & 2 & 0.25 & 2 & 0.25 & 0 & 0 & 1 & 0.13 \\
\hline Alluvial soil & 18 & 6.00 & 10 & 3.33 & 6 & 2.00 & 2 & 0.67 & 0 & 0 & 1 & 0.33 & 1 & 0.33 & 0 & 0 \\
\hline Brown pedocals & 60 & 4.62 & 33 & 2.54 & 22 & 1.69 & 7 & 0.54 & 1 & 0.08 & 2 & 0.15 & 0 & 0 & 1 & 0.08 \\
\hline Gray forest soil & 30 & 4.29 & 13 & 1.86 & 7 & 1.00 & 3 & 0.43 & 0 & 0 & 2 & 0.29 & 0 & 0 & 1 & 0.14 \\
\hline Bog soil & 32 & 5.33 & 18 & 3.00 & 9 & 1.50 & 2 & 0.33 & 1 & 0.17 & 3 & 0.50 & 1 & 0.17 & 2 & 0.33 \\
\hline Aeolian soil & 20 & 5.00 & 11 & 2.75 & 6 & 1.50 & 3 & 0.75 & 0 & 0 & 2 & 0.50 & 0 & 0 & 0 & 0 \\
\hline Meadow soil & 50 & 4.55 & 25 & 2.27 & 14 & 1.27 & 5 & 0.45 & 1 & 0.09 & 4 & 0.36 & 1 & 0.09 & 0 & 0 \\
\hline Solonetzs & 6 & 6.00 & 4 & 4.00 & 2 & 2.00 & 1 & 1.00 & 1 & 1.00 & 0 & 0 & 0 & 0 & 0 & 0 \\
\hline Chernozem & 29 & 4.14 & 14 & 2.00 & 6 & 0.86 & 3 & 0.43 & 0 & 0 & 3 & 0.43 & 1 & 0.14 & 1 & 0.14 \\
\hline Skeletol soil & 5 & 5.00 & 3 & 3.00 & 1 & 1.00 & 0 & 0 & 0 & 0 & 1 & 1.00 & 0 & 0 & 1 & 1.00 \\
\hline Castano-cinnamon soil & 19 & 4.75 & 9 & 2.25 & 6 & 1.50 & 2 & 0.50 & 0 & 0 & 0 & 0 & 1 & 0.25 & 0 & 0 \\
\hline Total & 650 & 4.68 & 348 & 2.50 & 193 & 1.39 & 76 & 0.55 & 9 & 0.06 & 45 & 0.32 & 10 & 0.07 & 15 & 0.11 \\
\hline
\end{tabular}

were isolated from all soil types except solonetzs and castano-cinnamon soils. The average number of strains belonging to Cystobacter was the highest in skeletol soils and the lowest in brown pedocals. The strains belonging to Pyxidicoccus were isolated from all soil types except litho soils, alluvial soils, gray forest soils, aeolian soils, chernozems, skeletol soil and castano-cinnamon soils. The average number of strains belonging to Pyxidicoccus was the highest in solonetzs and the lowest in castanozems. The strains belonging to Archangium were isolated from all soil types except saline soils, brown pedocals, gray forest soils, aeolian soils, solonetzs and skeletol soils. The average number of strains belonging to Archangium was the highest in litho soils and alluvial soils and the lowest in greycinnamon soils. The strains belonging to Mellittangium were isolated from all soil types except litho soils, alluvial soils, aeolian soils, meadow soils, solonetzs and castanocinnamon soils. The average number of strains belonging to Mellittangium was the highest in skeletol soils and the lowest in brown pedocals. In most soil types, the average strain number of Myxococcus ranked first, that of Corallococcus followed and the average strain number of Cystobacter ranked third. The average strain number of myxobacteria from the other three genera was significantly lower than that from the above three genera and in some soil types, myxobacteria from some genera were not even isolated.

Correlation analysis between the distribution of culturable myxobacteria and environmental parameters

The Pearson correlation coefficient was shown in Table 6.
The number of bacteriolytic myxobacteria and the total number of strains were weak positively correlated with water content, $\mathrm{pH}$ value, content of organic matter, content of hydrolytic nitrogen and content of available potassium, and weak negatively correlated with the content of available phosphorus. The number of celluloytic myxobacteria were weak positively correlated with water content and content of organic matter, and weak negatively correlated with the content of available phosphorus and content of available potassium, and no significant correlation with $\mathrm{pH}$ value and content of hydrolytic nitrogen. It could also be seen from the table that there was no significant correlation between the environmental parameters and the number of the bacteriolytic myxobacteria, the number of the celluloytic myxobacteria and the total number of strains. This may be due to the isolation and purification process of myxobacteria was cumbersome and difficult, resulting in the loss of some strains. On the other hand, it may be due to the addition of antibiotics in the culture medium damaged some myxobacteria, resulting in the varieties of isolated myxobacteria less. Therefore, the number of strains currently isolated did not very objectively represent the number of strains actually contained in the sample.

\section{Activity analysis of myxobacteria against $P$. infestans}

Among 348 strains of myxobacteria, 289 strains showed different degrees of inhibition on the growth of $P$. infestans, accounting for $83 \%$ of the total myxobacteria. Among them, 24 strains showed strong antagonistic activity with a 
diameter of inhibition zone more than $20 \mathrm{~mm}$. The inhibition zone diameter of 124 strains was $15 \sim 20 \mathrm{~mm}$. The inhibition zone diameter of 148 strains was $10 \sim 15 \mathrm{~mm}$. The inhibition zone diameter of only one strain was less than 10 mm (Fig. 4).

As shown in Table 7, the statistical analysis on the antagonistic activity of different species and genera of myxobacteria showed that Myxococcus had the highest percentage of resistant strains, $90.67 \%$. Corallococcus was next with a percentage of $86.84 \%$ for resistant strains. The percentage of resistant strains of Cystobacter and Mellittangium was $66.67 \%$. The percentage of the strains belonging to Pyxidicoccus with the activity against $P$. infestans was $44.44 \%$. The percentage of resistant strains of Archangium was $40 \%$.

\section{Discussion}

According to the analysis and statistics of soil environmental parameters in central Inner Mongolia, it was found that the soil samples in this area were basically neutral or alkaline, and the water content of soil samples was very low, generally in a dry state; the content of hydrolyzed nitrogen was in a state of deficiency; the content of organic matter and available potassium more than half of the soil samples were in a deficient state, while the content of available phosphorus was relatively high, only $36.70 \%$ of the soil samples were below the medium level, but the suitability of a single element cannot change the overall fertility status of this area. Ding et al. (2017) analyzed the physical and chemical properties of the soil in western Inner Mongolia and found that the soil in this area was basically neutral and alkaline, the water content was very low, and it was generally in a dry state. The average content of alkali nitrogen was very low. The average content of available potassium and organic matter were at a low level, while the average content of available phosphorus was high. This was basically the same as the physical and chemical properties of the soil in central Inner Mongolia. The analysis of soil nutrients in Guanzhong area of Shanxi Province by Zhao (2015) showed that the contents of organic matter, available nitrogen, available phosphorus and available potassium in the area are respectively in the fifth, fourth, third and second grades of soil nutrient grading standards. That is to say, except the organic matter in the state of deficiency, other environmental parameters were in the appropriate and above levels. Fu (2005) analyzed the soil resources in the vegetable base of Zhengzhou City of Henan Province and found that the soil fertility in the suburbs was medium. Apart from the low content of available phosphorus, the other nutrient contents were at a medium level. In comparison, it can be seen that the soil in the central part of Inner Mongolia is seriously arid and the soil fertility level is low, which can also explain a series of ecological environment deterioration problems such as severe sandstorm, desertification, and vegetation degradation in
Table 6: Person correlation coefficient of soil parameters and the distribution of myxobacteria

\begin{tabular}{llll}
\hline $\begin{array}{l}\text { Pearson correlation } \\
\text { coefficient }(\mathrm{r})\end{array}$ & $\begin{array}{l}\text { Bacteriolytic } \\
\text { myxobacteria }\end{array}$ & $\begin{array}{l}\text { Celluloytic } \\
\text { myxobacteria }\end{array}$ & $\begin{array}{l}\text { Total No. of } \\
\text { strains }\end{array}$ \\
\hline Water content & 0.093 & 0.012 & 0.072 \\
pH value & 0.089 & 0.000 & 0.063 \\
Organic matter & 0.013 & 0.005 & 0.012 \\
Available phosphorus & -0.017 & -0.009 & -0.016 \\
Hydrolytic nitrogen & 0.076 & 0.000 & 0.054 \\
Available potassium & 0.098 & -0.035 & 0.052 \\
$\begin{array}{l}|\mathrm{r}|<0.2 \text { is very low correlation. } 0.2 \leq|\mathrm{r}|<0.4 \text { is low correlation. } 0.4 \leq|\mathrm{r}|<0.7 \\
\text { for moderate correlation. } 0.7 \leq|\mathrm{r}|<0.9 \text { is highly correlated. } 0.9 \leq|\mathrm{r}|<1.0 \text { is } \\
\text { extremely high correlation }\end{array}$
\end{tabular}

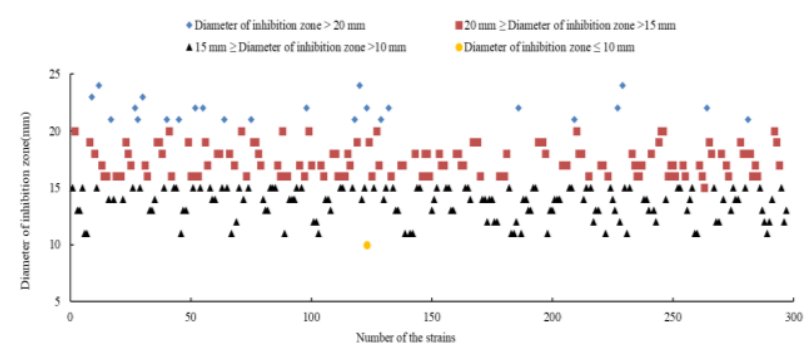

Fig. 4: Scatter diagram of inhibition zone diameter of myxobacteria strains against $P$. infestans

Table 7: Antibiotic activity of different species of myxobacteria against $P$. infestans

\begin{tabular}{llll}
\hline Species & $\begin{array}{l}\text { Total No. of } \\
\text { strains }\end{array}$ & $\begin{array}{l}\text { No. of strains } \\
\text { against } P .\end{array}$ & $\begin{array}{l}\text { Resistant } \\
\text { infestans }\end{array}$ \\
\hline Myxococcus fulvus & in) & \\
Myxococcus virescens & 41 & 64 & 95.52 \\
Myxococcus coralloides & 6 & 39 & 95.12 \\
Myxococcus xanthus & 45 & 5 & 83.33 \\
Myxococcus favescens & 19 & 41 & 91.11 \\
Myxococcus stipitatus & 10 & 15 & 78.95 \\
Myxococcus macrosporus & 5 & 7 & 70.00 \\
Corallococcus coralloides & 39 & 4 & 80.00 \\
Corallococcus exiguous & 27 & 35 & 89.74 \\
Corallococcus macrosporus & 8 & 24 & 88.89 \\
Corallococcus spp. & 2 & 6 & 75.00 \\
Pyxidicoccus fallax & 8 & 1 & 50.00 \\
Pyxidicoccus spp. & 1 & 4 & 50.00 \\
Cystobacter badius & 16 & 0 & 0.00 \\
Cystobacter violaceus & 25 & 11 & 68.75 \\
Cystobacter spp. & 4 & 17 & 68.00 \\
Archangium gephyra & 8 & 2 & 50.00 \\
Archangium spp. & 2 & 4 & 50.00 \\
Mellittangium spp. & 15 & 0 & 0.00 \\
Total & 348 & 10 & 66.67 \\
\hline
\end{tabular}

this area.

Morphological observation and 16S rRNA gene sequence analysis revealed that diversity of myxobacteria in the collected soil samples were rich. The isolated 348 strains of myxobacteria belonged to Cystobacterineae, including 278 strains of Myxococcaceae and 70 strains of Cystobacteraceae. Among them, there were 193 strains of Myxococcus, 76 strains of Corallococcus, 9 strains of Pyxidicoccus, 45 strains of Cystobacter, 10 strains of Archangium and 15 strains of Melittangium. The results 
indicated that myxobacteria had superior viability in the poor soil environment. These bacteria were the dominant genus of myxobacteria in central Inner Mongolia. Scientists have also found myxobacteria in soil samples collected in the Antarctic, which did not survive in the laboratory conditions. Myxococcus and Nannocystis have been found in the environment of $6^{\circ} \mathrm{C} \sim 8^{\circ} \mathrm{C}$ in the Alps for the first time (Menne and Rückert 1988) and traces of Myxococcus have also been found in the hot desert soil of Arizona (Reichenbach 1970). These findings indicated that myxobacteria can survive in extreme environment, indicating their strong survival ability, which is consistent with the result of this study. Charousová et al. (2017) isolated a total of 79 strains of myxobacteria from 10 soil samples collected in Slovakia, belonging to Myхососсиs, Corallococcus, Sorangium, and Polyangium. Li et al. (2014) used Semi-Nested PCR-DGGE technology to analyze 8 soils collected from Xinjiang and found 5 genera of myxobacteria, less than the genera found in this study. However, they also found the genera that were not present in this experiment, namely Stigmatella and Anaeromyxobacter. Wu et al. (2005) in Shandong University and Zhou (2013) used molecular hybridization and high-throughput sequencing technology to analyze the diversity of myxobacteria in the campus soil, and the results showed that myxobacteria in soil samples were rich in diversity. They covered almost all known families and a large number of unclassified myxobacteria. Therefore, we speculate that new myxobacterial resources may need to rely on new methods to isolate in the future.

According to the distribution of myxobacteria in the samples of different utilization types, 6 genus of myxobacteria were purified from the soil samples of cultivated land, grassland and woodland, while only 3 genus of myxobacteria were purified from the samples of unused land, namely Myхососсиs, Corallococcus and Cystobacter. In terms of myxobacteria population, 19 species of myxobacteria were purified from grassland samples. Cultivated land samples were followed by 18 species. 13 species of myxobacteria were purified from the woodland samples, while only 8 species were purified from the unused land samples. It can be seen that the utilization types of soil had a significant impact on the species and genus distribution of myxobacteria. Among them, the myxobacteria in the grassland and cultivated land samples were abundant, while the myxobacteria in the woodland and unused land samples are less. Charousová et al. (2017) isolated myxobacteria from alpine soil, forest soil and farmland soil of Slovakia, and found that Myxococcus and Corallococcus were the most widely distributed and the best source for myxobacteria was farmland soil. However, Li et al. (2005) and Ding (2017) respectively found that myxobacteria were the most abundant in the forest samples in Hebei Province and Ordos plateau, slightly different from the results of this study. The reason may be that the difference in the sampling location and the physical and chemical properties of the samples resulted in a difference in the population of myxobacteria in the soil samples of the same utilization type. It can be seen from the distribution of myxobacteria in the soil samples of different types that six genera of myxobacteria were purified from Fluvo-aquic soils, Grey-cinnamon soils, Castanozems and Bog soils, showing a rich diversity of myxobacteria. Among various types of soil, Fluvo-aquic soils, Grey-cinnamon soils, Castanozems and Bog soils are the relatively fertile soil types, while Aeolian soils is the relatively poor soil type, proving that myxobacteria grow better in the nutrient-rich environment. Although some environmental parameters of Skeletol soil were at the appropriate level, there was only one sample of Skeletol soils and Solonetzs, so the general significance of results is poor. This result was consistent with the study of $\mathrm{Li}$ et al. (2005) on the distribution of myxobacteria in samples of different properties.

The results of correlation analysis between the distribution of myxobacteria and environmental parameters showed that there was no significant correlation between them. There may be several reasons for this: Firstly, due to the cumbersome and difficult isolation and purification process of myxobacteria, some strains were lost during the isolation and purification process. Second, due to some pretreatment measures of the soil samples before isolation, some of the myxospores in the samples were possibly damaged to be unable to geminate normally. For example, generally, the samples were treated at $58^{\circ} \mathrm{C}$ for $12 \mathrm{~h}$ before isolation of myxobacteira. The pretreatment time may be too long. Third, due to the addition of antibiotics in the culture medium, some myxobacteria could be inhibited, resulting in fewer types of myxobacteria isolated. Therefore, the currently isolated strains do not very objectively represent the species actually contained in the sample, resulting in biased results. Zhou (2013) found that the abundance of myxobacteria was less correlated with temperature, $\mathrm{pH}$, content of organic carbon, carbon to nitrogen ratio, and had no correlation with precipitation and particle grading. The central region of Inner Mongolia has a vast territory and a large number of soil types. There are many reasons for the difference in the diversity of myxobacteria. In addition to the environmental factors studied in this paper, heavy metals, salinity, rainfall, topography and other factors may also affect the diversity of myxobacteria.

Several myxobacterial metabolites have been purified and shown to be bioactive and therefore myxobacteria represent an underexploited resource for bioactive discovery (Landwehr et al. 2016). In this study, the activity analysis of myxobacteria against $P$. infestans showed that 289 strains of 348 strains of myxobacteria showed different degrees of inhibition on the growth of $P$. infestans, and the percentage of resistant strains was as high as $83 \%$. Due to the growing population, more and more pesticides are used to improve the production of food, but they are generally highly toxic, and pesticide 
poisoning incidents occur every year. Potato is one of the world's four major food crops, after wheat, corn and rice, but its production is reduced annually due to tuber rot. Potato late blight is a devastating disease caused by $P$. infestans, which can cause the death of potato stem and leaves and rancid tuber (Kroon et al. 2011). Therefore, it is extremely urgent to develop effective and harmless pesticides to prevent and control potato late blight. In this study, most of the myxobacterial strains isolated from soil samples from central Inner Mongolia showed the activity in inhibiting the growth of potato late blight pathogen $P$. infestans providing a new idea for the research and development of effective pesticides for the prevention and control of potato late blight.

\section{Acknowledgements}

The authors acknowledge the efforts of Ye Dong and $\mathrm{Zi}$ Wen Guo for isolating the microorganism.

\section{Funding Source}

This study was supported by the National Natural Science Foundation of China (No. 31370058), Natural Science Foundation Program of Inner Mongolia, China (No. 2019MS03066), and the 10th Batch of "Grassland Elite" Project of Inner Mongolia, China (No. DC2000000758).

\section{Author Contributions}

Wu $\mathrm{ZH}$ and Liu HR conceived the experiments, Wu ZH, Wang XH and Ma Q conducted the experiments, Wu ZH, Ding YX and Zhao PY analysed the results. All authors reviewed the manuscript.

\section{Conflicts of Interest}

The authors declare that they have no conflicts of interest, and manuscript is approved by all authors for publication. There is no conflict of interest among the institutions regarding the research when it has been conducted at the institutions other than authors institutions. If such a conflicting situation arises, the authors will be held responsible.

\section{Data Availability}

The datasets generated during and/or analysed during the current study are available from the corresponding author on reasonable request.

\section{Ethics Approval}

This article does not contain any studies with human participants or animals performed by any of the authors.

\section{References}

Arias Del Anqel JA, AE Escalante, P Martinez-CastillaL, M Benitez (2017). An evo-devo perspective on multicellular development of myxobacteria. J Exp Zool B Mol Dev Evol 328:165-178

Boone DR, RW Castenholz (2004). Bergey's Manual of Systematic Bacteriology. Springer-Verlag, New York, USA

Charousová I, H Steinmetz, J Medo, S Javoreková, J Wink (2017). Soil myxobacteria as a potential source of polyketide-peptide substances. Folia Microbiol 62:305-315

Chen SH, CN Gong (2005). Regionalization of grassland climate characteristics and ecotypes in Inner Mongolia. Meteorol Sci Technol $33: 340-344$

Cui HC (2018). Study on the function of PiGK5 and phosphoproteomics analysis of sexual reproduction induced by hormone $\alpha 1$ in Phytophthora infestans. Dissertation. Inner Mongolia Agricultural University, China

Diez J, JP Martinez, J Mestres, F Sasse, R Frank, A Meyerhans (2012). Myxobacteria: Natural pharmaceutical factories. Microb Cell Fact $30: 11-52$

Ding YX (2017). Isolation and identification of myxobacteria from Ordos Plateau Area and preliminary analysis of their antibiotic activities against Phytophthora infestans. Dissertation. Inner Mongolia Agricultural University, China

Ding YX, RH Xie, AQ Gao, HR Liu (2017). Quantity of soil microbes and soil physiochemical properties in West Inner Mongolia. Arid Zone Res 34:1294-1303

Fu QL (2005). Evaluation of Soil Resource of Vegetable Production Base in Zhenzhou. Dissertation. Henan Agricultural University, China

Gaspari F, Y Paitan, M Mainini, D Losi, EZ Ron (2005). Myxobacteria isolated in Israel as potential source of new anti-infectives. J Appl Microbiol 98:429-439

Guo WJ, GJ Tao, WY Tao, FJ Cui, XC Jin, F Bi, ZH Xu, ZH Ao (2007). A Myxobacterium strain Sorangium cellulosum AHB125 producing epothilone B and other anticancer substances. Nat Prod Res 21:1256-1265

Haas BJ, S Kamoun, MC Zody (2009). Genome sequence and analysis of the Irish potato famine pathohen Phytophthora infestans. Nature 461:393-398

Herrmann J, AA Fayad, R Müller (2017). Natural products from myxobacteria: Novel metabolites and bioactivities. Nat Prod Rep 34:125-160

Ji TW (2005). Comparison on determining the organic matter contents in the soils by different heating methods in the potassium dichromatevolumetric method. Acta Agric Zhejian 17:311-313

Kim YJ, HJ Kim, GW Kim, K Cho, S Takahashi, H Koshino, WG Kim (2016). Isolation of coralmycins A and B, potent anti-gram negative compounds from the myxobacteria Corallococcus coralloides M23. J Nat Prod 79:2223-2228

Kroon L, H Brouwer, A Cock, F Govers (2011). The Phytophthora genus anno. Phytopathology 102:348-364

Landwehr W, C Wolf, J Wink (2016). Actinobacteria and myxobacteria two of the most important bacterial resources for novel antibiotics. Curr Top Microbiol Immunol 398:273-302

Li BY, Q Yao, HH Zhu (2014). Approach to analyze the diversity of myxobacteria in soil by semi-nested PCR-denaturing gradient gel electrophoresis (DGGE) based on taxon-specific gene. PLoS One 9; Article e108877

Li JY (2010). Determination of soil hydrolyzable nitrogen (alkaline hydrolysis diffusion method). Agric Sci Technol 10:15

Li LY, JZ Jiang, W Guo (2011). Screening of antagonistic bacteria against Phytophthora infestans and its inhibition effect. Plant Dis Pests 39: 14671-14675

Li YK, SM Zhang, FD Zhou (1982). Determination of soil available potassium by tetraphenylborate nephelometry. Chin J Soil Sci 10:39-42

Li YQ, LP Zhang, RL Yang (2005). Study on diversity of species resource of myxobacteria in Heibei province: Urban district and five counties of Chengde. J Heibei Univ Sci Technol 26:215-224 
Wu et al. / Intl J Agric Biol, Vol 25, No 6, 2021

Liu BH, L Yang, LF Feng, LX He (2011). Isolation and purification of myxobacteria in Chengdu. Anim Husb Feed Sci 3:25-27

Livingstone PG, RM Morphew, DE Whitworth (2018). Genome sequencing and pan-genome analysis of 23 Corallococcus spp. strains reveal unexpected diversity, with particular plasticity of predatory gene sets. Front Microbiol 9; Article 3187

Menne B, G Rückert (1988). Myxobakterien (myxobacterales) in höhlensedimenten des hagengebirges (nördliche Kalkalpen). Die Hohle Karst Hohlenkd 39:120-131

Okanya PW, KI Mohr, K Gerth, H Steinmetz, V Huch (2012). Hyaladione, an s-methyl cyclohexadiene-dione from Hyalangium minutum. J Nat Prod 75:768-770

Reichenbach H (2001). Myxobacteria, producers of novel bioactive substances. J Indus Microbiol Biotechnol 27:149-156

Reichenbach H (1970). Nannocystis exedens gen. nov., spec. nov., a new myxobacterium of the family Sorangiaceae. Arch Mikrobiol 70:119-138

Ren XB, ZL Zhang, PY Zhao, ZH Wu, HC Cui, HR Liu (2016). Isolation and identification of the strain YR-35 resistant to Phytophthora infestans and its metabolites. Chin J Biol Cont 32:379-387

Sood S, RP Awal, J Wink, KI Mohr, R Manfred (2014). Aggregicoccus edonensisgen. nov.,spp.nov., an unusually aggregating myxobacterium isolated from a soil sample. Intl J Syst Evol Microbiol 65:745-753

Sun Y, T Tomura, J Sato, T lizuka, R Fudou, M Ojika (2016). Isolation and biosynthetic analysis of haliamide, a new PKS-NRPS hybrid metabolite from the marine myxobacterium Haliangium ochraceum. Molecules 21:59-66

Wang DT, ZL Ma (2010). The molecular biology of myxobacterium. Chem Life 30:779-782

Weissman KJ, R Müller (2009). A brief tour of myxobacterial secondary metabolism. Bioorg Med Chem 17:2121-2136

Wenzel SC, R Müller (2009). Myxobacteria-'microbial factories' for the production of bioactive secondary metabolites. Mol Biosyst 5:567-574
Wu ZH (2018). Isolation of myxobacteria from the central region of Inner Mongolia and their activity and components against potato late blight pathogen. Dissertation. Inner Mongolia Agricultural University, China

Wu ZH, DM Jiang, P Li, YZ Li (2005). Exploring the diversity of mycobacteria in a soil niche by myxobacteria-specific primers and probes. Environ Microbiol 7:1602-1610

Xing XL, ZH Yue, RG Chen (2011). Determination and precautions of soil available phosphorus. Agric Henan 2:48-49

Xu SP, S Tao, J Cao (2001). Spatial structure pattern of soil pH, clay and organic matter contents in the Inner Mongolia area. Chin J Soil Sci $32: 145-148$

Ye HY, JC Zhang (1984). A measuring method of soil moisture. $J$ West Chin For Sci 1984:66-69

Zhang H, LP Ying, N Jiang, JD Wang, CX Wang (2011). New epothilone congeners from Sorangium cellulosum strain So0157-2. Nat Prod Res 25:1707-1712

Zhang JE (2006). Ecology Common Experimental Research Methods and Techniques. Chemical Industry Press, Beijing, China

Zhang Q (2005). The Isolation, Identification and Activity Assays of the Myxobacteria. Dissertation. Shanghai Normal University, Shanghai, China

Zhang ZD, YQ Xie, M Chu, MY Gu, SQ Song, QY Tang, J Mao (2010). Study on isolation and identification of endophytes in yam rhizome. Xinj Agric Sci 47:126-129

Zhou XL, W Shen, ZM Rao, ZX Wang, GJ Zhu (2004). A rapid method for preparation of fungal chromosome DNA. Microbiol Chin 31:89-92

Zhou XW (2013). Sub-population Census for Myxobacteria in Soil and Molecular Strategy Research for their Territoriality. Dissertation. Shandong University, Shandong, China

Zhao YT (2015). Spatial Characteristics and Changes of Soil Nutrients in Cultivated Land of Guanzhong Region in Shaanxi Province based on GIS. Dissertation. Northwest A \& F University, Xianyang, China 